\title{
Effects of cryopreservation on the motility characteristics of human spermatozoa
}

\author{
B. A. Keel, B. W. Webster and D. K. Roberts
}

Department of Obstetrics and Gynecology. The University of Kansas School of Medicine at Wesley Medical Center, The Center for Reproductive Medicine, 2212 East Central, Wichita, Kansas 67214,

U.S.A.

\begin{abstract}
Summary. Ejaculates (164) were obtained from 17 donors serving on an artificial insemination by donor panel. Semen analysis was performed before and after freezing by an integrated microcomputerized system employing the multiple-exposure photography (MEP) method. Sperm count, motility, velocity, motility index (MI; product of the sperm velocity and percentage of motile spermatozoa) and motile density (MD). were determined for each ejaculate. After the initial evaluation the ejaculates were frozen in liquid nitrogen, thawed $24 \mathrm{~h}$ later, and assessed for post-thaw motility, velocity, MI and MD. The mean \pm s.e. sperm count and volume for this group of donors was $148 \pm 4 \times 10^{6} / \mathrm{ml}$ and $3 \cdot 1 \pm 0 \cdot 1 \mathrm{ml}$, respectively. Mean \pm s.e. values obtained from the prefreeze analysis were: motility $=64 \pm 1 \%$, velocity $=$ $30 \pm 0.4 \mu \mathrm{m} / \mathrm{sec}, \quad \mathrm{MI}=19 \pm 0.5 \mu \mathrm{m} / \mathrm{sec}$ and $\mathrm{MD}=94 \pm 3 \times 10^{6} / \mathrm{ml}$. Post-thaw analysis revealed a significant reduction $(P<0.01)$ in all values measured. Motility was reduced to $27 \pm 1 \%$, MI was reduced to $5 \pm 0.3 \mu \mathrm{m} / \mathrm{sec}$, and $\mathrm{MD}$ was reduced to $33 \pm 1 \times 10^{6} / \mathrm{ml}$. Velocity was the least affected by cryopreservation, being reduced to $21 \pm 0.5 \mu \mathrm{m} / \mathrm{sec}(P<0.01)$. Cryopreservation resulted in a marked shift in the frequency distribution of sperm motility and motility index towards subnormal values while in the majority of ejaculates velocity and motile density were maintained in the normal range. Significant differences were noted amongst donors in the percentage change of the various semen measures as a result of cryopreservation. When withinsubject coefficients of variation were calculated, velocity was the least variable parameter. These results indicate that, while cryopreservation results in significant reductions in the number of motile spermatozoa in the ejaculate, the velocity is only marginally reduced.
\end{abstract}

\section{Introduction}

Artificial insemination with donor semen (AID) has been used successfully when male factors such as azoospermia, Rh incompatibility, and genetic disorders are indicated (Beck, 1974; Karow, 1980). Bunge \& Sherman (1953) first reported the use of cryopreserved human semen for AID. Since that time, frozen human semen has been used extensively for artificial insemination.

Cryopreserved semen has several advantages over the use of fresh semen, including ease of scheduling both donor and patient and assurance of availability of known quality donor semen. Moreover, cryopreservation allows for the quarantining of donor semen until appropriate quality control measures can be implemented to ensure that the ejaculate is free of infectious disease before insemination (see Greenblatt et al., 1986). However, fewer pregnancies have been reported using cryopreserved semen as compared to results utilizing fresh semen (Steinberger \& Smith, 1973; Ansbacher, 1978; Quinlivan, 1979; Smith et al., 1981; Richter et al., 1984). Reduced fertilizing ability of cryopreserved semen has been related to ultrastructural changes (Pederson \& Lebeck, 1971), decreased penetration of cervical mucus (Fjallbrant \& Ackerman, 1969; Urry et al., 1983) 
and decreased post-thaw survival (Keel \& Black, 1980), and motility (Smith \& Steinberger, 1973; Keel \& Karow, 1980; Thachil \& Jewett, 1981).

Several previous studies have examined the efficacy of various cryopreservation techniques for human semen (Zavos et al., 1980; Thachil \& Jewett, 1981; Cohen et al., 1981; Taylor et al., 1982; Serafini \& Marrs, 1986; Prins \& Weidel, 1986). However, few studies have evaluated the effects of freezing on the motility characteristics of spermatozoa. The commercial availability of an easy-touse microcomputerized system for precise measurement of semen parameters, including sperm velocity, has allowed more accurate description of semen characteristics (Burke \& Kapinos, 1985). In this report, we have utilized such a system to evaluate objectively the effects of cryopreservation on the motility characteristics of human spermatozoa. In addition, we have also examined the within- and between-subject variability of various semen characteristics before and after freezing.

\section{Materials and Methods}

The 164 ejaculates were obtained from 17 donors serving on an AID panel. Ejaculates were obtained by masturbation following 3 days of sexual abstinence. Semen was processed immediately upon liquefaction, and the semen analysis was performed at room temperature.

Quantitative, semi-automatic semen analyses were performed on undiluted semen $(8 \mu \mathrm{l})$ using a Makler Counting Chamber (Makler, 1980a). Preliminary studies indicated that results obtained using the Makler Chamber were highly correlated with results obtained using more subjective techniques for sperm count $(r=0.822, P<0.005$; $96.8 \pm 10.9 \times 10^{6} / \mathrm{ml}$ and $97.8 \times 10^{6} / \mathrm{ml}$ for Makler and haemocytometer, respectively) and sperm motility $(r=$ $0.758, P<0.005 ; 66.4 \pm 3.0 \%$ and $66.7 \pm 3.7 \%$ for Makler and subjective method, respectively). Semen analysis was performed at room temperature utilizing a commercially available microcomputerized, multiple exposure photography system (MEP) orignally described by Makler (1980b) (Zygotek Systems, Inc., Springfield, MA 01 103). The MEP method utilizing the Zygotek system has been described in detail elsewhere (Burke \& Kapinos, 1985). Briefly, the system consisted of an Olympus BH-2 microscope with a $\times 20$ phase-contrast objective, 7000 Polaroid $4 \times 5$ camera using type 57 black and white film, stroboscope, IBM PC computer, and a graphics tablet. The exposed positive Polaroid film was placed on the graphics tablet and analysed by the computer. This method provides results on sperm count $\left(\times 10^{6} / \mathrm{ml}\right)$, sperm motility $(\%)$, sperm velocity $(\mu \mathrm{m} / \mathrm{sec})$, motility index (MI; motility $\times$ velocity, $\left.\mu \mathrm{m} / \mathrm{sec}\right)$ and motile density (MD; motility $\times$ concentration, $\times 10^{6} / \mathrm{ml}$ ). Preliminary studies were initially performed to analyse the within-sample variation associated with the semen analysis system. For this study, 6 separate semen analyses were performed on a single ejaculate by the MEP method described above. The Makler chamber was washed between each analysis, and a fresh aliquant of the mixed semen $(8 \mu \mathrm{l})$ was applied to the chamber. The results of this study are shown in Table 1. The coefficient of variation for the various semen values ranged from 6 to $10 \%$. The overall pooled coefficient of variation was $15 \%$.

Table 1. Variation associated with the computerized MEP system

\begin{tabular}{lrrrc}
\hline Parameter & Mean & s.d. & Range & CV\%* \\
\hline Count $\left(\times 10^{6} / \mathrm{ml}\right)$ & 109 & 13 & $89-125$ & 12 \\
Motility $(\%)$ & 52 & 6 & $47-62$ & 11 \\
Velocity $(\mu \mathrm{m} / \mathrm{sec})$ & 34 & 2 & $31-36$ & 6 \\
Motile density $\left(\times 10^{6} / \mathrm{ml}\right)$ & 56 & 11 & $47-78$ & 20 \\
Motility index $(\mu \mathrm{m} / \mathrm{sec})$ & 17 & 2 & $15-21$ & 14 \\
\hline
\end{tabular}

Six separate analyses were performed on a single ejaculate.

*Pooled CV $\%=15 \%$.

After semen analysis, the ejaculate was frozen in liquid nitrogen using glycerol as the cryoprotectant as described previously (Keel \& Karow, 1980). Briefly, glycerol was added drop-wise to the semen with constant mixing to a final concentration of $10 \%(\mathrm{v} / \mathrm{v})$. The diluted semen was aspirated in $0.5 \mathrm{ml}$ straws and placed horizontally at $4^{\circ} \mathrm{C}$ for $30 \mathrm{~min},-85^{\circ} \mathrm{C}$ for $10 \mathrm{~min}$ and subsequently plunged directly into liquid nitrogen for storage. After $24-72 \mathrm{~h}$, an aliquant was thawed rapidly in running tap water and allowed to equilibrate to room temperature $(15 \mathrm{~min})$. Semen analysis on the thawed specimen was repeated as described above. 
Statistical analysis was performed using one-way analysis of variance and Duncan's test when appropriate. For the purposes of calculating frequency distributions of ejaculates having normal semen characteristics, the following normal values established in our laboratory were used: sperm motility, $\geq 40 \%$; sperm velocity, $\geq 20 \mu \mathrm{m} / \mathrm{sec}$; motile density, $\geq 8 \times 10^{6} / \mathrm{ml} ;$ motility index, $\geq 8 \mu \mathrm{m} / \mathrm{sec}$.

\section{Results}

\section{Semen analysis data}

The semen analysis data for all ejaculates studied are shown in Table 2. Cryopreservation resulted in significant $(P<0.01)$ reductions in velocity, motility, motility index and motile density.

Table 2. Semen analysis data from human ejaculates before and after cryopreservation

\begin{tabular}{lrc}
\hline Parameter & \multicolumn{1}{c}{ Prefreeze } & \multicolumn{1}{c}{ Post-thaw } \\
\hline Volume $(\mathrm{ml})$ & $3 \cdot 1 \pm 0 \cdot 08$ & - \\
Count $\left(\times 10^{6} / \mathrm{ml}\right)$ & $148 \cdot 2 \pm 4 \cdot 3$ & - \\
Motility $(\%)$ & $63 \cdot 8 \pm 1 \cdot 1^{\mathrm{d}}$ & $27 \cdot 4 \pm 1 \cdot 3^{\mathrm{c}}$ \\
Velocity $(\mu \mathrm{m} / \mathrm{sec})$ & $30 \cdot 3 \pm 0 \cdot 4^{\mathrm{c}}$ & $20 \cdot 8 \pm 0 \cdot 5^{\mathrm{b}}$ \\
Motility index $(\mu \mathrm{m} / \mathrm{sec})$ & $19 \cdot 1 \pm 0 \cdot 5^{\mathrm{b}}$ & $5 \cdot 3 \pm 0 \cdot 3^{\mathrm{a}}$ \\
Motile density $\left(\times 10^{6} / \mathrm{ml}\right)$ & $93 \cdot 5 \pm 3 \cdot 4^{\mathrm{e}}$ & $32 \cdot 5 \pm 1 \cdot 3^{\mathrm{c}}$ \\
\hline
\end{tabular}

Means identified by different superscript letters are statistically different $(P<0.01)$ by one-way ANOVA and Duncan's test.

\section{Frequency distributions of normal and abnormal semen parameters}

The frequency distributions of ejaculates having normal and abnormal semen parameters before and after freezing are illustrated in Fig. 1. Nearly all $(96 \%)$ ejaculates displayed prefreeze sperm motilities of $\geq 40 \%$ (Fig. 1a) Cryopreservation caused a marked shift in the distribution to the left, resulting in $83 \%$ of ejaculates having post-thaw motilities of $<40 \%$ (Fig. 1a). Greater than $98 \%$ of the ejaculates examined had prefreeze sperm velocities, motile densities and motility indices in the normal range (Figs 1b-d). Significant shifts in the distribution to the left were noted for all three measures after cryopreservation (Figs $1 \mathrm{~b}-\mathrm{d}$ ). Post-thaw sperm velocities of $<20 \mu \mathrm{m} / \mathrm{sec}$ were displayed by $39 \%$ of ejaculates (Fig. 1b), the post-thaw motility index $(<8 \mu \mathrm{m} / \mathrm{sec}$ ) was subnormal for most ejaculates $\left(82 \%\right.$ ) (Fig. 1c). Post-thaw motile densities of $<8 \times 10^{6} / \mathrm{ml}$ occurred in $8 \%$ of ejaculates (Fig. 1d).

\section{Percentage change of semen measures among donors}

Of the 17 donors evaluated, 5 donors produced 10 or more ejaculates (total of 123 ejaculates) during the period of study. The semen analysis values of these ejaculates were used to compare the percentage change of semen measures among donors as a result of cryopreservation. As shown in Table 3, sperm motility was decreased $57 \%$ among all donors. Donors C, D and E displayed a similar percentage change in motility. In contrast, Donor A demonstrated a $32 \%$ change in sperm motility while that in Donor B was decreased $80 \%$ as a result of cryopreservation. The percentage changes in sperm motility for Donors $\mathbf{A}$ and $\mathbf{B}$ were significantly different from each other and from the other 3 donors. Velocity was reduced for all ejaculates studied (Table 3). Donors A, B, C and E 

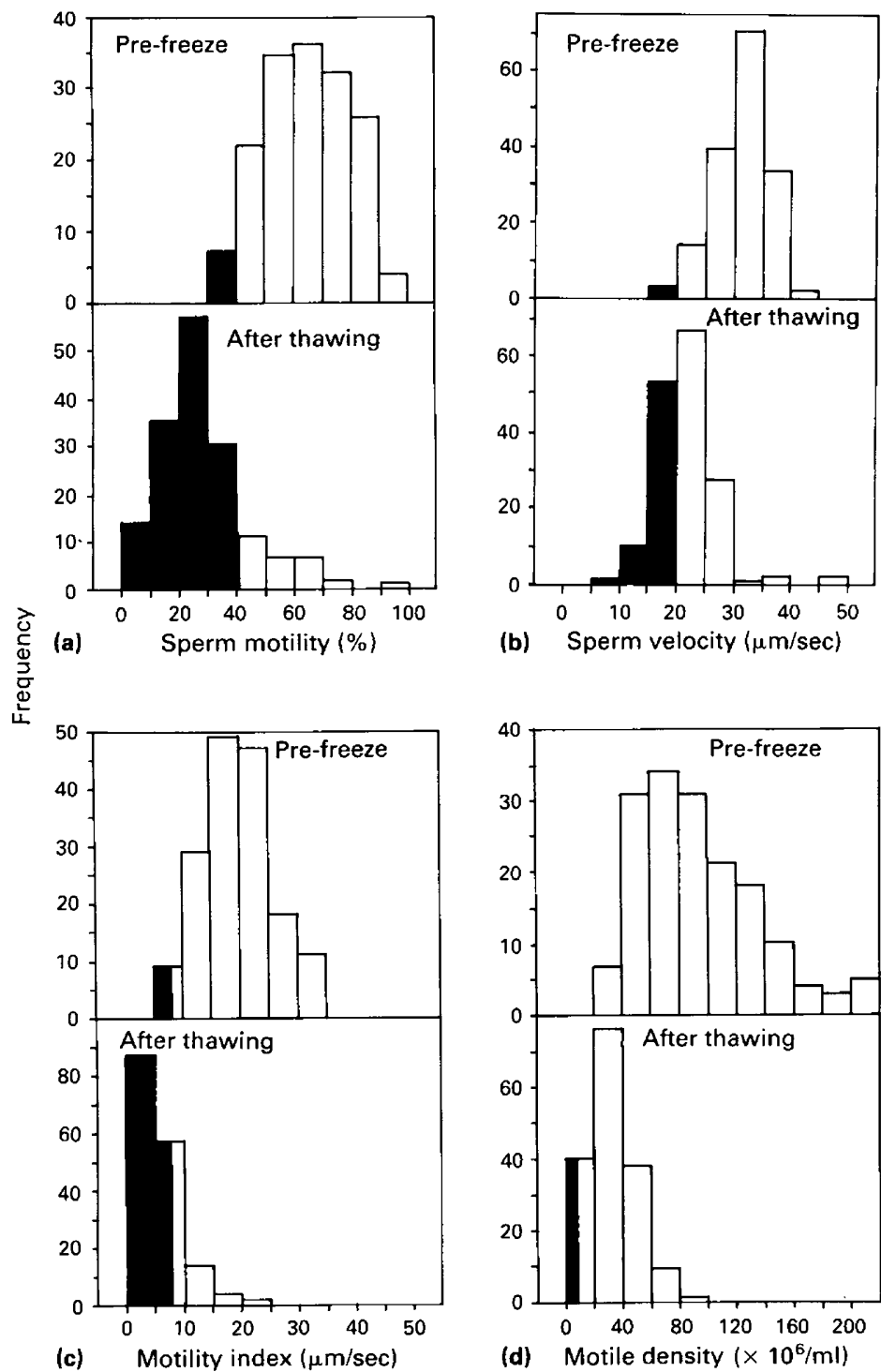

(b) Sperm velocity $\langle\mu \mathrm{m} / \mathrm{sec}\rangle$

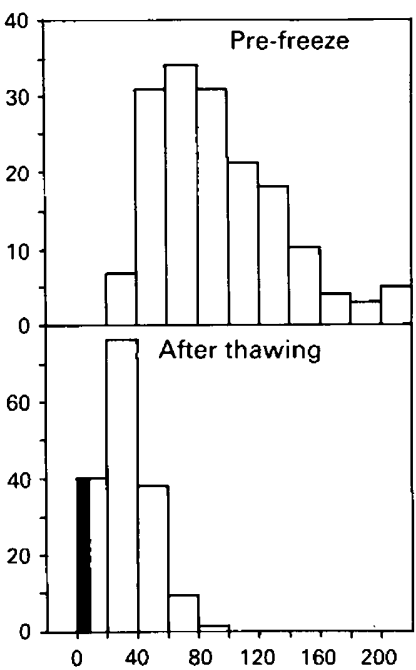

(d) Motile density $\left(\times 10^{6} / \mathrm{ml}\right)$

Fig. 1. Frequency distribution histogram displaying the number of ejaculates (frequency) having prefreeze (top) and post-thaw (bottom) values for (a) sperm motility; (b) sperm velocity; (c) motility index; and (d) motile density. Open bars refer to ejaculates having normal values; closed bars refer to ejaculates having subnormal values.

displayed identical changes in velocity. In marked contrast, velocity in Donor D was essentially unaltered as a result of cryopreservation. MI and MD were reduced for all ejaculates (Table 3) and in both cases, the percentage change associated with Donor A was significantly less while the percentage change associated with Donor B tended to be greater than that of the other donors.

\section{Within-subject coefficients of variation}

The data obtained from these 5 donors were also used to calculate pooled within-subject coefficients of variation (CV\%) for each semen measure before and after freezing (Table 4$)$. The 
Table 3. Percentage change* of semen data amongst 5 donors after cryopreservation of the semen

\begin{tabular}{|c|c|c|c|c|c|}
\hline \multicolumn{2}{|c|}{ Donor } & Motility & Velocity & $\begin{array}{c}\text { Motility } \\
\text { index }\end{array}$ & $\begin{array}{l}\text { Motile } \\
\text { density }\end{array}$ \\
\hline $\begin{array}{l}\text { A } \\
\text { B } \\
\text { C } \\
\text { D } \\
\text { E }\end{array}$ & $\begin{array}{l}(n=24) \\
(n=20) \\
(n=55) \\
(n=10) \\
(n=14)\end{array}$ & $\begin{array}{l}32 \cdot 5 \pm 5^{\mathrm{bc}} \\
70 \pm 2^{\mathrm{e}} \\
52 \pm 2^{\mathrm{d}} \\
55 \pm 5^{\mathrm{d}} \\
54 \pm 9^{\mathrm{d}}\end{array}$ & $\begin{array}{c}31 \pm 3^{\mathrm{bc}} \\
35 \pm 2^{\mathrm{bc}} \\
30 \pm 2^{\mathrm{b}} \\
0 \cdot 2 \pm 9^{\mathrm{a}} \\
33 \pm 3^{\mathrm{bc}}\end{array}$ & $\begin{array}{l}51 \pm 6^{\text {d }} \\
82 \pm 1^{r} \\
69 \pm 2^{\text {e }} \\
61 \pm 5^{\text {de }} \\
76 \pm 3^{\text {ef }}\end{array}$ & $\begin{array}{l}41 \pm 3^{\mathrm{c}} \\
73 \pm 2^{\text {ef }} \\
57 \pm 2^{\mathrm{d}} \\
61 \pm 6^{\mathrm{de}} \\
72 \pm 3^{\mathrm{ef}}\end{array}$ \\
\hline All & $(n=164)$ & $57 \pm 2$ & $30 \pm 2$ & $72 \pm 2$ & $62 \pm 2$ \\
\hline
\end{tabular}

*(Prefreeze value - post-thaw value $) /$ prefreeze value $\times 100$.

Values are expressed as the mean \pm s.e. Means identified by different superscript letters are statistically different $(P<0.05)$ by one-way ANOVA and Duncan's test.

Table 4. Average within-subject variation of human semen values before and after cryopreservation

\begin{tabular}{lrrrrrrrr}
\hline & \multicolumn{3}{c}{ Prefreeze } & & \multicolumn{3}{c}{ Post-thaw } \\
\cline { 2 - 4 } \cline { 7 - 8 } & Mean & s.d. & CV\% & & Mean & s.d. & CV\% \\
\hline Motility $(\%)$ & 65 & 11 & 17 & & 31 & 12 & 39 \\
Velocity $(\mu \mathrm{m} / \mathrm{sec})$ & 30 & 3 & 10 & & 21 & 4 & 19 \\
Motility index $(\mu \mathrm{m} / \mathrm{sec})$ & 20 & 4 & 20 & & 6 & 3 & 50 \\
Motile density $\left(\times 10^{6} / \mathrm{ml}\right)$ & 100 & 32 & 32 & & 38 & 13 & 34 \\
Count $\left(\times 10^{6} / \mathrm{ml}\right)$ & 157 & 35 & 22 & & - & - & - \\
\hline
\end{tabular}

Values based upon 123 samples from 5 donors, range $=10-55$ samples/donor.

$\mathrm{CV} \%$ ranged from 10 to $32 \%$ before freezing, with velocity demonstrating the least variation within-subjects and motile density the greatest variation. As a result of cryopreservation, the CV\% was increased about 2-fold for motility, velocity and motility index. The within-subject variation associated with motile density was not altered by the freezing process. Post-thaw velocity displayed the least amount of within-subject variation while the $\mathrm{CV} \%$ was the greatest for post-thaw motility index.

\section{Discussion}

Traditional methods for analysing sperm count and motility are fraught with highly variable and often unpredictable results. Research during the past 5-10 years has been directed towards replacing subjective methods of estimating sperm count and motility with more objective methods that will also provide accurate information concerning sperm kinetics. The multiple exposure photography (MEP) system originally described by Makler $(1978,1980 \mathrm{~b})$ is one such system. The recent commercial availability of an MEP system (Burke \& Kapinos, 1985) that replaces the more cumbersome projection system of the original Makler method (Makler, 1978, 1980b) has allowed for accurate in-office determination of sperm count, motility and velocity on a routine basis. In this study we have used the MEP system to evaluate accurately the effects of cryopreservation on sperm motility characteristics.

Repeated analysis of a single sample utilizing the MEP system revealed a pooled coefficient of variation for all parameters measured of $15 \%$. The highest amount of variation was associated with 
motility index and motile density, which are mathematically derived from two empirical parameters (motility and velocity, and count and motility, respectively) and probably represent combined variation associated with both of these measures. Originally, the results obtained from multiple MEP analyses of single samples from two different specimens were evaluated (Makler, 1978). The coefficients of variation for sperm count, motility and velocity can be calculated from the data in Table 2 of the paper by Makler (1978). It averaged 6-12\% which compares favourably with the findings of the present study. Therefore, the MEP system utilized herein produces reliable and reproducible objective information.

The average sperm count obtained for all specimens analysed by the MEP method was $148 \times 10^{6} / \mathrm{ml}$ and agrees with the results of Keel \& Karow (1980) and Steinberger \& Smith (1973) who reported mean sperm counts of $151 \times 10^{6} / \mathrm{ml}$ and $149 \times 10^{6} / \mathrm{ml}$, respectively, for frozen semen. The average prefreeze motility reported here is somewhat lower than the observations of others (Steinberger \& Smith, 1973; Keel \& Karow, 1980) and probably reflects the techniques used for motility determination. Makler (1978) previously reported that subjective estimates of motility yield a value about $20 \%$ higher than those determined objectively. Prefreeze velocity in this study averaged $30 \mu \mathrm{m} / \mathrm{sec}$. This value is in agreement with those of others who have evaluated prefreeze velocities by MEP in a population of semen donors (Cohen et al., 1981; Serafini \& Marrs, 1986) (29 and $33 \mu \mathrm{m} / \mathrm{sec}$, respectively). Mathur et al. (1986), utilizing cinematography to evaluate sperm velocity, observed a mean swimming speed of $30 \mu \mathrm{m} / \mathrm{sec}$ for fertile donors and suggested that this value may define a discriminatory boundary between fertile and infertile men. Similar conclusions have been reached by others (Milligan et al., 1980; Holt et al., 1985). However, because of the known effects of temperature on sperm velocity (Milligan et al., 1978; Makler et al., 1981), care must be taken when comparing velocity measured at room temperature (present study) versus $37^{\circ} \mathrm{C}$.

The motility index, originally defined by MacLeod (1951), is calculated in this study by the product of sperm velocity and motility. This calculation is an attempt to characterize the kinetics of spermatozoa by a single measure. Burke \& Kapinos (1985) observed that the motility index of spermatozoa was markedly increased by sperm rise techniques, and Mathur et al. (1986) reported that the motility index value for fertile men was significantly higher than for infertile men. The average motility index value reported by Mathur et al. (1986) for fertile men is comparable to the findings of the present study $(17 \mu \mathrm{m} / \mathrm{sec}$ and $19 \mu \mathrm{m} / \mathrm{sec}$, respectively). The relative significance of the motility index in the evaluation of male infertility remains to be established.

Cryopreservation resulted in a significant reduction in the semen parameters measured. Sperm motility was reduced by over $50 \%$ representing a percentage recovery (percentage survival) of $43 \%$. Percentage recoveries of $34-76 \%$ have been reported by several previous studies (Behrman \& Sawada, 1966; Smith \& Steinberger, 1973; Beck \& Silverstein, 1975; Keel \& Black, 1980; Keel \& Karow, 1980; Taylor et al., 1982), and depend to a large extent upon the cryoprotectant and the method of freezing employed. Cohen et al. (1981) and Serafini \& Marrs (1986), utilizing a similar MEP system, observed percentage survival rates of about $35-36 \%$. In the present study, the postthaw motile density was only $35 \%$ of the prefreeze value. Taken together, these studies indicate a $60 \%$ loss of the number of motile spermatozoa as a result of cryopreservation.

Cohen et al. (1981) and Serafini \& Marrs (1986) noted that the average velocity of cryopreserved spermatozoa was slightly but not significantly lowered compared with prefreeze values. In contrast, we have observed a statistically significant reduction in velocity as a result of cryopreservation. The reasons for this discrepancy are at present not apparent. Perhaps the larger number of ejaculates analysed in the present study $(n=164)$ compared with those studied by Serafini \& Marrs (1986) $(n=59)$ and Cohen et al. (1981) $(n=19)$ may have allowed for more accurate statistical comparison. However, although a statistical reduction in velocity was observed, this value was affected the least by cryopreservation, suggesting that the average speed of sperm forward progression is the most stable semen measure in relation to cryopreservation.

Virtually all ejaculates evaluated $(95 \%)$ had prefreeze sperm motilities, velocities, motile 
densities and motility indexes which were in the 'normal range' as established in our laboratory. Cryopreservation not only resulted in a significant reduction in these parameters but markedly shifted the values into the 'subnormal' or 'suboptimal' range. Suboptimal semen parameters are most often cited as the reason for the reported reduced fertility potential of frozen-thawed semen. In a recent elegantly designed study in which patients attending an AID clinic received both fresh and frozen semen from the same donor (thus the patient served as her own control), the fertility potential of fresh semen was 3 times greater than the frozen counterpart (Richter et al., 1984). However, these authors point out that the reduced fertility potential of frozen semen observed in that study may have been related to inadequate minimum criteria for post-thaw semen values. In support of this possibility, Bordson et al. (1986) observed no significant differences in the fecundity rates between fresh and frozen semen when the minimum number of post-thaw spermatozoa inseminated was at least $40 \times 10^{6}$ grade 3 motile spermatozoa. Therefore, poor fecundity of frozen semen may be related to the practice of inseminating an adequate number of progressively motile spermatozoa.

Significant differences were noted in the sensitivity of semen from different donors to cryopreservation. In general, most donors displayed a similar percentage decrease in motility, velocity, motility index and motile density as a result of freezing but there were some notable exceptions. Semen from Donor A exhibited a greater resistance to changes in motility, motility index, and motile density, while semen from Donor B proved to be the most sensitive to cryopreservation. Donor $\mathrm{D}$ exhibited marked resistance to alterations in sperm velocity. These data point to the difficulty in predicting the outcome of ejaculates subjected to freeze-thaw procedures. The reasons for the differences in sensitivity of donor spermatozoa to cryopreservation remain to be elucidated.

Of the semen parameters measured in the present study, velocity proved to be the least variable. On the other hand, motile density appeared to be associated with the greatest within-subject variation. Post-thaw analysis revealed an overall increase in within-subject variation, with velocity again showing the greatest reproducibility within donors. Considerable variation within semen donors has been reported previously (Poland et al., 1985). The relatively small sample size in the present study precludes accurate comparison of within-subject variation with that of other studies. The results presented here do, however, clearly suggest that (1) considerable variation exists within donors with respect to prefreeze semen parameters, (2) this variation is markedly increased after cryopreservation, (3) velocity appears to be the most stable semen characteristic measured, and (4) motility density and motility index display the greatest variation.

We thank Ms Kris Zumbach for technical assistance and Ms Dorothy Clark for the preparation of this manuscript. Supported by the Women's Research Institute, Wichita, Kansas.

\section{References}

Ansbacher, R. (1978) Artificial insemination with frozen spermatozoa. Fert. Steril. 29, 375-379.

Beck, W.W. (1974) Artificial insemination and semen preservation. Clin. Obstet. Gynec. 17, 115-125.

Beck, W.W. \& Silverstein, I. (1975) Variable motility recovery of spermatozoa following freeze preservation. Fert. Steril. 26, 863-867.

Behrman, S.J. \& Sawada, Y. (1966) Heterologous and homologous inseminations with human semen frozen and stored in a liquid nitrogen refrigerator. Fert. Steril. 17, 457-466.

Bordson, B.L., Ricci, E., Dickey, R.P., Dunaway, H., Taylor, S.N. \& Curole, D.N. (1986) Comparison of fecundability with fresh and frozen semen in therapeutic donor insemination. Fert. Steril. 46, 466-469.
Bunge, R.G. \& Sherman, J.K. (1953) Fertilizing capacity of frozen human spermatozoa. Nature, Lond. 172, $767-768$.

Burke, R.K. \& Kapinos, L.J. (1985) The effect of in vitro sperm capacitation on sperm velocity and motility as measured by an in-office, integrated, microcomputerized system for semen analysis. Int. J. Fertil. 30, 10-17.

Cohen, J., Felten, P. \& Zeilmaker, G.H. (1981) In vitro fertilizing capacity of fresh and cryopreserved human spermatozoa: a comparative study of freezing and thawing procedures. Fert. Steril. 36, 356-362.

Fjallbrant, B. \& Ackerman, D.R. (1969) Cervical mucus penetration in vitro by fresh and frozen-preserved human semen specimens. J. Reprod. Fert. 20, 515-517. 
Greenblatt, R.M., Handsfield, H.H., Sayers, M.H. \& Holmes, K.K. (1986) Screening therapeutic insemination donors for sexually transmitted diseases; overview and recommendations. Fert. Steril. 46, 351-364.

Holt, W.V., Moore, H.D.M. \& Hillier, S.G. (1985) Computer-assisted measurement of sperm swimming speed in human semen: correlation of results with in vitro fertilization assays. Fert. Steril. 44, 112-119.

Karow, A.M., Jr (1980) Human gametes. In Organ Preservation for Transplantation, 2nd edn. Eds A. M. Karow, Jr \& D. E. Pegy. Marcel Dekker, New York.

Keel, B.A. \& Black, J.B. (1980) Reduced motility longevity in thawed human spermatozoa. Archs Androl. 4, 213-215.

Keel, B.A. \& Karow, A.M. (1980) Motility characteristics of human sperm, nonfrozen and cryopreserved. Archs Androl. 4, $205-212$.

Macleod, J. (1951) Semen quality in one thousand men of known fertility and in eight hundred cases of infertile marriage. Fert. Steril. 2, 115-137.

Makler, A. (1978) A new multiple exposure photography method for objective human spermatozoal motility determination. Fert. Steril. 30, 192-199.

Makler, A. (1980a) The improved ten-micrometer chamber for rapid sperm count and motility evaluation. Fert. Steril. 33, 337-338.

Makler, A. (1980b) Use of the elaborated multiple exposure photography (MEP) method in routine sperm motility analysis and for research purposes. Fert. Steril. 33, 160-166.

Makler, A.D., Deutch, M., Vilensky, A. \& Palti, Y. (1981) Factors affecting sperm motility VIII, Velocity and survival of human spermatozoa as related to temperatures above zero. Int. J. Androl. 4, 559-569.

Mathur, S., Carlton, M., Ziegler, J., Rust, P.F. \& Williamson, H.O. (1986) A computerized sperm motion analysis. Fert. Steril. 46, 484-488.

Milligan, M.P., Harris, S.J. \& Dennis, K.J. (1978) The effect of temperature on the velocity of human spermatozoa as measured by time-lapse photography. Fert. Steril. 30, 592-594.

Milligan, M.P., Harris, S. \& Dennis, K.J. (1980) Comparison of sperm velocity in fertile and infertile groups as measured by time-lapse photography. Fert. Steril. 34, 509-511.

Pederson, H. \& Lebeck, P.E. (1971) Ultrastructural changes in the human spermatozoa after freezing for artificial insemination. Fert. Steril. 22, 125-133.
Poland, M.L., Moghissi, K.S., Giblin, P.T., Ager, J.W. \& Olson, J.M. (1985) Variation of semen measures within normal men. Fert. Steril. 44, 396-400.

Prins, G.S. \& Weidel, L. (1986) A comparative study of buffer systems as cryoprotectants for human spermatozoa. Fert. Steril. 46, 147-149.

Quinlivan, W.L. (1979) Therapeutic donor insemination: results and causes of nonfertilization. Fert. Steril. 32, $157-160$.

Richter, M.A., Haning, R.V. \& Shapiro, S.S. (1984) Artificial donor insemination: fresh versus frozen semen; the patient as her own control. Fert. Steril. 41, $277-280$.

Serafini, P. \& Marrs, R.P. (1986) Computerized stagedfreezing technique improves sperm survival and preserves penetration of zona-free hamster ova. Fert. Steril. 45, 854-858.

Smith, K.D. \& Steinberger, E. (1973) Survival of spermatozoa in a human sperm bank. J. Am. Med. Ass. 223, 774-777.

Smith, K.D., Rodriquez-Rigau, L.J. \& Steinberger, E. (1981) The influence of ovulatory dysfunction and timing of insemination on the success of artificial insemination donor (AID) with fresh or cryopreserved semen. Fert. Steril. 36, 496-502.

Steinberger, E. \& Smith, K.D. (1973) Artificial insemination with fresh or frozen semen. J. Am. Med. Ass. 223, $778-783$.

Taylor P.J., Wilson, J., Laycock, R. \& Weber, J. (1982) A comparison of freezing and thawing methods for the cryopreservation of human semen. Fert. Steril. 37, 100-103.

Thachil, J.V. \& Jewett, M.A. (1981) Preservation techniques for human semen. Fert. Steril. 35, 546-548.

Urry, R.L., Carrell, D.T., Hull, D.B., Middleton, R.G. \& Wiltbank, M.C. (1983) Penetration of zona-free hamster ova and bovine cervical mucus by fresh and frozen human spermatozoa. Fert. Steril. 39, 690-694.

Zavos, P.M., Goodpasture, J.C., Zaneveld, L.J. \& Cohen, M.R. (1980) Motility and enzyme activity of human spermatozoa stored for 24 hours at +5 degrees Celsius and -196 degrees Celsius. Fert. Steril. 34, $607-609$. 